\title{
Oil Spill Management in Nigeria: SWOT Analysis of the Joint Investigation Visit (JIV) Process
}

\author{
Akpofure Rim-Rukeh \\ Department of Environmental Science, Federal University of Petroleum Resources, Effurun, Nigeria \\ Email: arimrukeh@yahoo.co.uk
}

Received 3 January 2015; accepted 26 March 2015; published 27 March 2015

Copyright (C) 2015 by author and Scientific Research Publishing Inc.

This work is licensed under the Creative Commons Attribution International License (CC BY). http://creativecommons.org/licenses/by/4.0/

(c) (i) Open Access

\section{Abstract}

The Joint Investigation Visit (JIV) process of the National Oil Spill Detection and Response Agency (NOSDRA) have been analysed using the Strength, Weakness, Opportunity and Threat (SWOT) methodology. The oil spill Joint Investigation Visit (JIV) is empowered by the Oil Spill Recovery, Clean-up, Remediation and Damage Assessment Reulations, 2011 Section 5. The strength of the JIV process lies within its participatory nature and the well defined legal structure of the process. The oil spill Joint Investigation Visit process in Nigeria has several weaknesses-lack of independence and oversight, lack of technical competence on the part of regulatory bodies, lack of technical competence on the part of community representative, lack of transparency on the part of oil companies, lack of general procedure for determining the actual cause of spill, lack of general procedure for determining the actual volume of oil spilled, determination on the size of the impacted area and exclusion of women from the JIV Process. The JIV process for oil spill presents a number of opportunities such as; increasing community awareness, growing consciousness through Non Governmental Organisations (NGOs) and capacity building of stakeholders. Possible threats to the JIV process include; poor governance and corruption, manipulation of the Process by the spiller through the start date of an oilspill and obvious lack of transparency. Improved effectiveness of the JIV process will depend on strengthening of government agency coordination, integrated decision-making adequate training to various stakeholders and supporting infrastructure for purposeful monitoring and enforcement.

\section{Keywords}

Joint Investigation Visit, National Oil Spill Detection and Response Agency, Nigeria, SWOT Analysis, Oil Spill, Community Trepresentatives 


\section{Introduction}

Oil is the main source of energy in the industrial world today [1] and by any standard, Nigerian's most economic resource as it contributes nearly 90 percent of government revenue [2]. Globally the oil market's infrastructure moves petroleum products/oil from the producing regions to the consuming regions. During storage or transport, and occasionally as the result of exploration activities, oils and other oil-based products are sometimes spilled onto land or into waterways. Oil spill therefore, is an inevitable consequence of the ever-increasing demand for exploration, production, transportation and use of oil.In the Niger Delta, there is an extensive network of pipelines between the fields and flowstations and oil terminals.

Oil spill is the uncontrolled release of crude oilinto the environment. The causes and circumstances of oil spills are many and varied. Possible causes of spill incidence in Nigeria are well documented in literature; operational (equipment) failures and human factor [3], corrosion of pipelines and storage tanks [4], over-aged pipelines and other production infrastructure [5], fire and and explosion during drilling operation [6], loading and discharging operations at the terminal [7], allisions/collisions of oil carrying vessels [8], bunkering activities and crude oil theft process [9] and pipeline vandalization (sabotage) [10].

The economic, human and environmental consequences of oil spill are great. When oil spillage occurs, the beauty or the aesthetics of the ecology is damaged [11]. Oil introduced to the environment can elicit gross biological damage, physiological effects on the biota (both plants and animals) and a broad range of ecological changes [12]. Petroleum hydrocarbons can affect and cause changes in many organisms at all levels; cellular, organismic and ecosystems. Effects on marine organisms range across a spectrum from toxicity (especially for light oils and products) to smothering (heavier oils and weathered residues) [13]. The presence of toxic components does not always cause mortality, but may induce temporary effects like narcosis and tainting of tissues, which usually subside over time.Other environmental impacts of oil spill may include: restriction of recreational use of such water bodies [14], non-availability of clean water for cooling purposes for industries located water bodies [14], and disruption of routine harbor activities such as ferry services [14]. In addition, when oil spills on surface of water bodies such as streams, rivers and lakes, it alters the quality of the water such that it makes it unfit for human consumption. It has been speculated that, one barrel of crude oil can make one million barrels of water undrinkable [15] [16], disruption of fisheries activities [13], and most importantly oil spill have been reported topose a significant potential for adverse human health effects [17]. In tropical regions, mangrove swamps provide an extremely rich and diverse habitat as well as coastal protection and important nursery areas and in the event oil spillbreathing roots of mangroves are smothered [18]. Oil spill have detrimental effects on the economy of a nation in multi dimensional forms. For example, in September 17, 1999 Shell Petroleum Development Company (SPDC) oil pipeline was vandalized at Ekakpramre in Ughelli-South Local Government Area of Delta State where about 100,000 barrels of oil was spilled and all oil fields in area had to be shut in. The economic loss of the incident was estimated to be over \$10,000 million dollars (that is, over N110 billion) [19]. Another case was the vandalization of Petroleum Product Marketing Company (PPMC) pipeline at Jesse in Ethiope-West Local Government Area and at Oviri-Court in Okpe Local Government Area, both of Delta State in October, 1998 and July, 2000 respectively. Over 2000 lives were lost in both incidents [20].

In every oil spill situation, it is critical for the responders to understand the physical processes that cause the oil to move and spread and the distribution of the pollutant as it moves through the environment (marine or land). When a major oil spill occurs, it must be contained, clean up, and ensure that damage to human health and the environment is minimized. Without careful planning and clear organization, efforts to deal with large oil spills could be slow, ineffective, and potentially harmful to response personnel and the environment. In response to this the Federal Ministry of Environment (FMENv) established the National Oil Spill Detection and Response Agency (NOSDRA) through an act of parliament NOSDRA Establishment Act, CAP N157, LFN 2006.

The Agency is charged with responsibility for preparedness, detection and response to all oil spillages in Nigeria. Accordingly, the NOSDRA Act provides that the objectives of NOSDRA shall be to co-ordinate and implement the National Oil Spill Contingency Plan for Nigeria.

The National Oil Spill Contingency Plan as may be formulated (or revised) from time to time, by the Federal Government which coordination and implementation shall be the objective of NOSDRA includes:

1) Safe, timely, effective and appropriate response to major or disastrous oil pollution;

2) Identify high-risk areas as well as priority areas for protection and clean-up;

3) Establish the mechanism to monitor and assist or where expedient direct the response, including the capa- 
bility to mobilizing the necessary resources to save lives, protect threatened environment, and clean up to the best practical extent, the impacted site;

4) Maximize the effective use of the available facilities and resources of corporate bodies, their international connections and oil spill co-operatives, that is Clean Nigeria Associates in implementing appropriate spill response;

5) Ensure funding and appropriate and sufficient pre-positioned pollution combating equipment and materials, as well as functional communication network system required for effective response to major oil pollution;

6) Provide a programme of activation, training and drill exercise to ensure readiness to oil pollution preparedness and response and the management and operational personnel;

7) Co-operate and provide advisory services, technical support and equipment for purposes of responding to major oil pollution incident in the West African sub-region upon request by any neighbouring country, particularly where a part of the Nigerian territory may be threatened;

8) Provide support for Research and Development (R \& D) in the local development of methods, materials and equipment for oil spill detection and response;

9) Cooperate with the International Maritime Organization and other national, regional and international organizations in the promotion and exchange of results of research and development programme relating to the enhancement of the State of the art of the oil pollution preparedness and response, including technologies, techniques for surveillance, containment, recovery, disposal and clean up to the best practical extent;

10) Establish agreements with neighbouring countries regarding the rapid movement of equipment, personnel and supplies into and out of the countries for emergency oil spill response activities;

11) Determine and preposition vital combat equipment at most strategic areas for rapid response;

12) Establish procedures by which the Nigerian Customs Service and the Nigerian Immigration Services shall ensure rapid importation of extra support response equipment and personnel;

13) Develop and implement an appropriate audit system for the entire plan;

14) Carry out such other activities as are necessary or expedient for the full discharge of its functions and the execution of the Plan under this Act.

Inasmuch as the functions of NOSDRA are partially embedded in the gamut of its objectives as espoused above, the NOSDRA Act for the avoidance of doubt, went on to specify and detail the functions of NOSDRA in Section 638 as follows,

"The Agency shall be responsible for surveillance and ensure compliance with all existing environment allege slation and detection of oil spills in the petroleum sector; receive reports of oil spillages and co-ordinate oil spill response activities throughout Nigeria; co-ordinate the implementation of the Plan as may be formulated, from time to time, by the Federal Government; co-ordinate the implementation of the Plan for the removal of hazardous substance as may be issued by the Federal Government; perform such other functions as may be required to achieve the aims and objectives of the Agency under this Act or any Plan as may be formulated by the Federal Government pursuant to this Act."

The NOSDRA Act went on to provide that; the Agency shall act as the lead Agency for all matters relating to oil spills response management and can make regulations for the purpose of protecting the Nigeria environment. In pursuance to this, NOSDRA promugated the Oil Spill Recovery, Clean-up, Remediation and Damage Assessment Reulations, 2011. Section 5 of the Regulation is on oil spill Joint Investigation Visit (JIV)—-“A joint investigation team comprising the owner or operator of the spiller facility, Community and State Government representatives and the Agency, shall be constituted immediately after an oil spill notification, visit the spill site and investigate the cause and event of the spillage and a report of their findings prepared by the Agency in accordance with the Fourth Schedule to these Regulations". However, the statutory Joint Investigation Visit (JIV) process has been the subject of controversy over years [21] [22]. This paper examines in details the JIV process in Nigeria highlighting its strength, weakness, opportunity and threat (SWOT). The SWOT is based on authors' experiences gained over the years as an environmental consultant. This paper concludes with some realistic steps that can be employed by all parties to improve the effectiveness and transparency of the JIV process.

\subsection{The Joint Investigation Visit (JIV) Process}

When an oil spill occurs in the Niger Delta, a joint investigation team should be mobilized to visit the site. The 
joint investigation team includes representatives of regulatory agencies, the oil company, the affected community and the security forces.

Several regulatory agencies participate in the JIV process. They are:

- The National Oil Spill Detection and Response Agency (NOSDRA).

- The Department of Petroleum Resources and

- Representatives of State Ministries of Environment.

The joint investigation team investigates the cause(s) of the oil spill and is supposed to jointly agree and sign a report that confirms the cause(s) and includes other key information such as the volume and spread of crude oil spill and the area affected. In addition, the JIV is to make recommendations based on observations.

\subsection{The JIV Form}

The information generated from the observation is recorded on the oil spill investigation form, known as a Joint Investigation Visit (JIV) Form (Appendix A). It is extremely important to state that the basis for deciding whether communities receive compensation for damage to their homes, fields and fisheries is dependent on the content of JIV form. The data recorded on JIV form about the volume of oil spilt and area affected can also affect how much compensation people receive, and may affect the extent and quality of clean up. The form records the date on which the spill is believed to have started, the date of the investigation, the cause of the spill (often with various choices already printed on the form to be ticked as appropriate), the volume spilt and the area affected. The JIV form is generally short document of three pages. If a spill is found to be due to sabotage or third party interference then the community gets no compensation from the oil company, regardless of the damage caused. This is based on a provision in Nigeria's Oil Pipelines Act, which states:

"The holder of a licence shall pay compensation... to any person suffering damage (other than on account of his own default or on account of the malicious act of a third person) as a consequence of any breakage of or leakage from the pipeline or an ancillary installation, for any such damage not otherwise made good." [23].

\section{Study Methodology}

In this study, the technique of SWOT analysis was employed. SWOT analysis is a structured planning method used to evaluate the Strengths, Weaknesses, Opportunities, and Threats of a project. The technique is a commonly used to assist in identifying strategic direction for an organization or practice [24].

- Strengths: characteristics of the project that give it an advantage over others;

- Weaknesses: are characteristics that place the team at a disadvantage relative to others;

- Opportunities: elements that the project could exploit to its advantage;

- Threats: elements in the environment that could cause trouble for the project.

It is preferred for the present work as it yields useful information about the future viability of the JIV process for the purpose of stemming conflictual relationship between oil producing companies and host communities. The strengths and weaknesses of a system are determined by internal elements, whereas external forces dictate opportunities and threats.

\section{Outcomes of the SWOT Analysis}

\subsection{Strengths}

Strength identifies resources and capabilities of the JIV process, which may aid to develop the process further. The strength of the oil spill Joint Investigation Visit process in Nigeria lies in the following:

\subsubsection{The JIV Process Is Participatory in Approach}

A participatory process is a family of approaches, methods and behaviour that enable the local people express and analyze the realities of their lives and conditions to plan for themselves what action to take and to monitor and evaluate the results [25]. [26] describes participatory process as a growing family of approaches and methods to enable the intended beneficiaries to share, enhance and analyze their knowledge of life and conditions to plan and act. It involves talking with the people rather than talking to the people. It is a bottom-up participa- 
tory approach. Participatory methods promote greater efficiency, effectiveness and sustainability [27].

The strength and advantages of participatory methods lies in its capability of promoting community's awareness and the production of a realistic action plan by community people. It enhances community's sense of responsibility, confidence, and ownership of externally funded projects. It also promotes sustainability because projects sited in the communities function for a longer time. Participatory methods promote the transfer of technology and increase the income generating capacity of the people. The joint investigation visit team as statutorily constituted includes representatives of regulatory agencies, the Oil Company, representatives of the affected community and the security forces and must be signatories to JIV Form for it to gain acceptance.

\subsubsection{Well-Defined Legal Structure}

The activities of NOSDRA especially as it concerns Joint Investigation Visit (JIV) to oil spill site is well defined in appropriate regulations in Nigeria. The Oil Spill Recovery, Clean-up, Remediation and Damage Assessment Regulations, 2011, Section 5 clearly spelt out the Joint Investigation Visit (JIV) process. In addition, the establishment of National Oil Spill Detection and Response Agency (NOSDRA) is back by the act of parliament (NOSDRA Establishment Act, CAP N157, LFN 2006).

In addition, the constitution of the Federal Republic of Nigeria, as the national legal order, recognizes the importance of improving and protecting the environment and makes provision for it. Relevant sections are:

Section 20 makes it an objective of the Nigerian State to improve and protect the air, land, water, forest and wildlife of Nigeria.

Section 12 establishes, though impliedly, that international treaties (including environmental treaties) ratified by the National Assembly should be implemented as law in Nigeria.

Sections 33 and 34 which guarantee fundamental human rights to life and human dignity respectively, have also being argued to be linked to the need for a healthy and safe environment to give these rights effect.

\subsection{Weaknesses}

The oil spill Joint Investigation Visit process in Nigeria has several weaknesses. It is perceived merely as a bureaucratic requirement by Government to satisfy the yearning of the local people [21] [22].

\subsubsection{JIV Investigations-Lacking Independence and Oversight}

Oil spill investigations are organized and led by oil company personnel. Despite its title, the National Oil Spill Detection and Response Agency (NOSDRA) do not initiate oil spill investigations. It is usually dependent on the company (the spiller) both to take NOSDRA staff to oil spill sites and to supply technical data about spills. NOSDRA is told when it will be done by the oil companies - either by text or a letter. JIVs are frequently carried out days—and in some cases weeks—after an oil spill occurs [22].

This is inconsistent with the requirements of Nigerian regulations. According to the Environmental Guidelines and Standards for the Petroleum Industry in Nigeria clean-up of an oil spill should commence within 24 hours of the occurrence of the spill. As JIV precedes clean-up, it is impossible to comply with the 24 hour deadline when JIVs are scheduled several days after the spill is reported. NOSDRA appears to have little control over the timeframe for investigations.

The weakness of the regulatory agencies means that, in effect, the company (which is the potentially liable party) has substantial control over a process that sets many of the parameters for liability. These include the cause of the spill, the volume of oil spilt, the area affected and the scale and extent of the resulting impact. The company's dominant role in the investigation process represents a deeply troubling conflict of interest.

\subsubsection{Investigations-Lack of Technical Competence on the Part of Regulatory Bodies}

The technical capacity of regulatory bodies is also a matter of concern. This has been similarly observed by United Nations Environment Programme (UNEP). In 2011environmental assessment of Ogoniland, the United Nations Environment Programme (UNEP) found:

"Both [the Department of Petroleum Resources] and NOSDRA suffer from a shortage of senior and experienced staff who understand the oil industry and can exercise effective technical oversight." [28].

The issue of shortage of manpower on the part of regulatory agencies was made manifest when in one oil spill 
case a student on industrial working experience (know as industrial training) was the sole regulatory representative sent by Rivers State Ministry of Environment for the JIV [22]. Amnesty International and CEHRD (full meaning) have also collaborated the issue of technical competence on the part oil regulators [29].

\subsubsection{Investigations-Lack of Technical Competence on the Part of Community Representative}

Oil companies claim that the involvement of community members in the JIV process is intended to improve the credibility of the process. However, the lack of technical competence on the part of community representative has been reported [21]. For example, the cause of a spill is determined by brainstorming and by such diagnostic tools as the location of the hole or leak point on the pipe. Terms such as, "if spills are at 12 o'clock it is sabotage and but if it is 6 o'clock it is corrosion," are novel to the community representatives.

\subsubsection{Lack of Transparency on the Part of Oil Companies}

Lack of transparency in the JIV process is another weakness observed over time. Lack of transparency is the relatively limited involvement of community representative in the JIV process. In most cases, very few member of the community are able to participate in the process, and larger percentage of others is asked to sign incomplete JIV forms. In some cases, community representatives are denied a copy of the JIV form, even after signing it. In addition it is fifth copy of the signed JIV form that is handed over to the community. Amnesty International and CEHRD have also collaborated the issue of lack of transparency on the part oil regulators [29].

\subsubsection{Lack of General Procedure for Determining the Actual Cause of Spill}

Establishing the cause of an oil spill has long been the main focus of the JIV process. However, the means by which the cause of an oil spill is decided during the JIV are deeply flawed. Different oil companies have their own method of establishing the cause of a spill, because of lack of an acceptable procedure for determining the actual cause of spill. The current method of using the position or point of the leak (if spills are at 12 o'clock it is sabotage, it is almost always sabotage. Even at nine, ten, eleven or three, two or one o'clock, it is mostly sabotage, but if it is 6 o'clock it is corrosion) is loaded with controversy [21].

For example, Nigeria Agip Oil Company (NAOC) determines the cause of spill through visual observation, Ultrasonic Thickness Measurements (UTM) results and evaluation of the circumstances surrounding the spill. Visual observation involves an inspection of the nature of the aperture, hole or breach. From such inspection, it is possible to determine whether a spill is due to hacksaw cut, drilled hole (which will give a consistent/regular circular appearance), corrosion (which shows pitting and irregularity at the edges of the aperture) or use of explosive devises (which shows indentations and gashes on the facility). UTM provides results on the thickness of the pipe which enables one to determine whether the thickness of the pipe is still within the corrosion allowance as specified for the pipeline. For equipment failure, it is possible to determine impairment in the integrity of concerned facility, for instance a pin hole in the welded joint of a choke box or failure of seal in a clamp. Spill incidents caused by oil theft for instance are verified from the observation of the valves installed for the oil theft activity. The outcome of these findings is discussed among the members of the JIV team and a decision is reached to confirm the findings [4].

Shell Petroleum Development Company (SPDC) and Total establish cause of oil spill using visual indicators including the nature of the hole/leak point and whether there has been prior disturbance of soil [30].

\subsubsection{Lack of General Procedure for Determining the Actual Volume of Oil Spilled}

Accurate measurement of the volume of oil spilt is important for two reasons: firstly, it can affect assessment of damage done and therefore compensation people receive and the nature of the clean up undertaken; secondly, it is the basis for the overall figures that companies put into the public domain on volume of oil spilt due to operational failures versus sabotage and theft.

During the JIV process at oil spill sites the volume of oil spilt is recorded. According to almost all sources interviewed the method used to calculate volume involves a visual estimation of the area over which oil has spread multiplied by the depth of the spill, with some consideration of issues such as the porosity of the soil. The method of "estimation" of actual volume of spilled oil is another weakness in the in the JIV process. For community members involved in JIVs the focus of the process is often the cause of the spill, which people know affects whether they get any compensation. 


\subsubsection{Determination on the Size of the Impacted Area}

JIV forms also record the area impacted by an oil spill. This data can affect both the extent of clean up and the amount of compensation communities received (assuming the cause is operational). Again, the methodology used to identify and record the impacted area is extremely weak.

Current method of determining the area impacted by the spill is based on estimation. However, JIVs consistently fail to capture photos clearly displaying the real extent of the oil spill impact areas. This is a serious concern as there is no record of the impact to challenge what is recorded. Moreover, while "estimation" may capture the most obviously affected areas it will likely fail to identify impacts not visible including the impacts on water systems and on down-stream communities.

\subsubsection{Exclusion of Women from the JIV Process}

Another weakness observed in the JIV process is the exclusion of women. In the Niger Delta prevalent cultural norms reinforce patriarchal structures of power and present men as primary decision-makers in family and community affairs. Women are generally excluded from critical meetings with representatives of oil companies operating in the area. Despite their exclusion from the key processes, women in the Niger Delta have often been at the forefront of protest actions about the impacts of pollution.

The exclusion of women from the JIV process not only means they lack information-it can affect the extent to which impacts of oil spills on women's lives are recorded and addressed. When a community is affected by an oil spill, compensation is often negotiated with male community representatives, as an overall "package". The damage done to individuals can be lost in the course of these negotiations, and more powerful members of the community may benefit while others, including women, lose out.

Companies frequently fail to conduct a full assessment of the damage caused to individual property, and the overall "package" agreed by the community leaders is often not enough to repair all individual properties. Moreover, the negotiation process with the community leaders is open to abuse. This includes reports of benefit capture by those negotiating with the company, which can leave many people affected by oil pollution without any effective remedy.

The informal compensation system can place women at a particular disadvantage. Most "negotiations" are carried out by chiefs and youths, who are almost always male, even when women's activities in agriculture and fisheries are affected by oil industry damage.

\subsection{Opportunities}

The JIV process for oil spill presents a number of opportunities if it is properly conducted. After over 50 years of oil exploration and exploitation in the Niger Delta area, the people are becoming environmentally conscious.

\subsubsection{Increasing Community Awareness}

Increasing awareness and growing public pressure are demanding action to stop further environmental degradation. The demand for better environment is forcing a policy shift. In response to this stress, government has been setting emission standards for various pollutants, whereas industries in turn have focused on achieving emission goals. Globally, people are challenging the decisions of government where industrial growth is favoured over environmental protection. The investigation activities of oil spill are an opportunity for increasing community awareness.

\subsubsection{Growing Consciousness through Non Governmental Organisations (NGOs)}

For the past few decades, environmental groups are taking initiatives to develop activities in raising public awareness and public involvement in decision-making process. They play a multidimensional role, which includes capacity building of civil organisations with emphasis on the principles of sustainable development and creating a forum to facilitate the implementation of regulations involving community people [21]. Their campaigns empower communities by furnishing information on environmental laws, policies and effects of environmental damages. These NGOs are catalysing a participatory movement involving women and youth, school and university students, towards environmental protection. The aims of the environmental movement are to improve information disclosure and engaging various stakeholders in the process of managing environmental goods. 


\subsubsection{Capacity Building of Stakeholders}

It is very essential to to state that major stakeholders in the JIV process are the community representatives. In addition, it is necessary to sensitize, inform and train stakeholders to make them understand the significance of JIV process. Capacity building of regulatory agencies in terms of staff, technical expertise and monitoring facilities is an opportunity that can be explored.

\subsection{Threats}

Several advantages and opportunities have been realized in JIV process, yet certain threats exist:

\subsubsection{Poor Governance and Corruption}

Good governance comprises a cluster of ideas that Western governments claim constitute a "a model for good economic and political management" [31]. Excessive bureaucratic requirements, inefficient and complex administrative procedures may pose hurdles to any environmental reforms. Public disclosure of information and accountability are lacking. All above mentioned factors and governance failure has potential to encourage corruption, which may results in misuse of scarce public resources. Corrupt payoffs, i.e., bribes, may be made to override the legal norms. As at today, corruption has become a critical consideration in NOSDRA JIV process.

\subsubsection{Manipulation of the Process by the Spiller-Establishing the Start Date of an Oil Spill}

Establishing the start date of an oil spill is important in relation to both timely action to address the spill and calculations about the amount of oil spilt. There are two ways in which oil companies in the Niger Delta establish a spill has occurred: one is when companies detect a drop in pressure in the pipelines; the other is physical surveillance by staff or contractors. Over years it has been observed that most spills are reported by surveillance contractors who live in the community or by members of the community. Both of the methods of establishing that a leak is occurring have limitations in terms of how the start date of a leak is established, and pressure loss in itself would not alert companies to all leaks.

One of the greatest threats to the JIV process is the manipulation by the oil spiller on the actual date of spill. NOSDRA admits it is not always possible to know when a spill starts. This action by oil spiller has over the years angered the host communities.

\subsubsection{Lack of Transparency}

Communities are supposed to be involved in the JIV process. However, in the entire JIV process, there is obvious lack of transparency as most steps such as, determination of cause of spill are not known to the community people. The community claims they only participated in the joint investigation because they saw that it was taking place.

\section{Improving the Oil Spill Joint Investigation Visit Process}

Re-Designing of the JIV Forms: In the current JIV form, the cause of an oil spill is recorded by ticking a preset list of options - most of which are based on visual observation of the affected part of the oil pipe or wellhead and the surrounding area. Newer JIVs forms should include drawings, photographs and-often-additional observations made in writing. Ensure that photographs are clear and provide verifiable evidence of the cause and impacted area.

Review of Oil Spill Recovery, Clean-up, Remediation and Damage Assessment Regulations, 2011. For the purposeful implementation of Oil Spill regulation, the Agency should take steps to to strengthen its regulatory role. Substantially strengthen the capacity of NOSDRA especially in the area of increased budget all ocation for its operations, to develop a comprehensive and transparent JIV Process and uniform reporting format that takes into account the perspectives of all actors. To take steps to address gender discrimination. To mandate all oil producing companies to publish, annually, asset integrity data and to disclose the age of infrastructure and all repairs and replacements.

Determination of the Volume of Spill: Overhaul the way the volume of oil spilt is calculated, through the use of best available technologies and the publication of verifiable evidence.

Security Monitoring of Infrastructure: Significantly improve security monitoring of oil infrastructure to prevent sabotage and theft and commit to implementing best available technology to prevent spills in the Niger 
Delta.

Capacity Building for all Stakeholders: Solutions to oil pollution in the Niger Delta can only be approached meaningfully if all stakeholders are operating on a level playing field. All stakeholders must have access to the same information and the ability to challenge past bad practice that undermines trust and the formulation of future solutions.

Appointment of a Credible NGO to also witness the JIV Process: In order to increase transparency, public trust and acceptability of the JIV process, it is recommended that a credible NGO should be satutorily appointed into JIV committee.

\section{Conclusions}

In Nigeria, there are sufficient legal provisions for oil spill management especially it concerns Joint Investigation Visit (JIV). However, there are systemic flaws in the JIV process for investigating oil spills in the Niger Delta. As a result, the outcome of these investigations lacks credibility. There is no meaningful check on the oil companies' operations. Moreover, the lack of transparency around the oil spill investigation process is one of the factors that contribute to heightened tensions in the Niger Delta.

To address the critical issues, political commitment and public participation are indispensable. Improved effectiveness will also depend on strength of government agency coordination, integrated decision-making adequate training to various stakeholders and supporting infrastructure for purposeful monitoring and enforcement. It is required that JIV process be regularly revisited for progressive refinement that should not only remove existing constraints but also take care of future challenges.

\section{References}

[1] Duffy, J.J., Peake, E. and Mohtadi, M.F. (1980) Oil Spill on Land as Potential Source of Ground Water. Environmental International, 3, 107-120. http://dx.doi.org/10.1016/0160-4120(80)90045-8

[2] Okoko, K.A.B. and Nna, J.N. (1997) Emerging Trends and Community Perception in the Nigerian Oil Industry. Nigerian Journal of Oil and Politics, 1, 44-55.

[3] Cacciabue, P.C. (2000) Human Factors Impact on Risk Analysis of Complex Systems. Journal of Hazardous Materials, 71, 101-116. http://dx.doi.org/10.1016/S0304-3894(99)00074-6

[4] Osam, M.U., Wegwu, M.O. and Uwakwe, A.A. (2011) The Omoku Old Pipeline Oil Spill: Total Hydrocarbon Content of Affected Soils and the Impact on the Nutritive Value of Food Crops. Archives of Applied Science Research, 3, 514521.

[5] Okhamina, O. (2012) Explosion Rocks Chevrons, Oil Rig on Bayelsa State. The Vanguard News Paper.

[6] Clark, R.B. (1999) Marine Pollution.14th Edition, Oxford University Press, London, 161.

[7] Yip, T.L., Talley, W.K. and Jin, D. (2011) The Effectiveness of Double Hulls in Reducing Vessel-Accident Oil Spillage. Marine Pollution Bulletin, 62, 2427-2432. http://dx.doi.org/10.1016/j.marpolbul.2011.08.026

[8] Rim-Rukeh, A., Ikhifa, G.O., Imide, I.O. and Uduh, D. (2008) Community Based Intervention as a Strategy to Combat Pipeline Vandalization in the Niger Delta Area of Nigeria. Global Journal of Environmental Sciences, 7, $23-28$.

[9] Molvaer, E. (2013) Oil Theft in Nigeria: A Murky Business. The Economist, 4, 11-14.

[10] Joseph, E.O., Jeffery, G.J. and Stephen, S.K. (1996) The Clean-Up Cost, Technologies and Techniques of Bioremediation. Journal of Environmental Studies, 6, 99-114.

[11] Clinton, H.I., Ujagwung, G.U. and Horsfall, M. (2009) Evaluation of Total Hydrocarbon Levels in Some Aquatic Media in an Oil Polluted Mangrove Wetland in the Niger Delta. Applied Ecology and Environmental Research, 7, 111 120. http://dx.doi.org/10.15666/aeer/0702_111120

[12] Briggs, K.T., Yoshida, S.H. and Gershwin, M.E. (1996) The Influence of Petrochemicals and Stress on the Immune System of Seabirds. Regulatory Toxicology and Pharmacology, 23, 145-155. http://dx.doi.org/10.1006/rtph.1996.0036

[13] Rim-Rukeh, A. (2009) Environmental Science: An Introduction. Kraft Books, Ibadan.

[14] Osibanjo, O. and Ajayi, S.O. (1981) Pollution Studies on Nigeria Rivers II, Water Quality of Some Nigeria Rivers. Environmental Research Series B, 2, 87-95.

[15] Uzoekwe, S.A. and Achudume, A.C. (2011) Pollution Status and Effect of Crude Oil Spillage in Ughoton Stream Ecosystem in Niger Delta. Journal of Ecology and The Natural Environment, 3, 469-473. http://dx.doi.org/10.5897/JENE11.071 
[16] Ordinioha, B. and Sawyer, W. (2010) Acute Health Effects of a Crude Oil Spill in a Rural Community in Bayelsa State, Nigeria. Nigerian Journal of Medicine, 19, 140-144. http://dx.doi.org/10.4314/njm.v19i2.56500

[17] Getter, C.D., Ballou, T.G. and Koons, C.B. (1985) Effects of Dispersed Oil on Mangroves: Synthesis of a Seven-Year Study. Marine Pollution Bulletin, 16, 318-324. http://dx.doi.org/10.1016/0025-326X(85)90447-3

[18] NDES, Niger Delta Environmental Survey (2003) Phase 1: Report on the Niger Delta Environment.

[19] Human Rights Watch Briefing Paper: Update on Human Rights Violations in the Niger Delta, December $14,2001$.

[20] Environmental Right Action/Friends of the Earth Nigeria ERA/FoEN (2014) Agip Manipulates Oil Spill Joint Investigation (JIV) Report in Ikarama/Kalaba Community. Report No. 354.

[21] Amnesty International Report (2013) Bad Information-Oil Spill Investigation in the Niger Delta. Report Index: AFR 44/028/2013.

[22] Oil Pipelines Act of 2004.

[23] Hill, T. and Westbrook, R. (1997) SWOT Analysis: It’s Time for a Product Recal. Long Range Planning, 30, 46-52. http://dx.doi.org/10.1016/S0024-6301(96)00095-7

[24] Chambers, R. (1983) Rural Development: Putting the Last First. Longman, London.

[25] Chambers, R. (1994) Participatory Rural Appraisal: Challenges, Potentials and Paradigm. World Development, 22, 1437-1454. http://dx.doi.org/10.1016/0305-750X(94)90030-2

[26] Overseas Development Administration, ODA (1995) A Guide to Social Analysis for Projects in Developing Countries. HMSO, London.

[27] UNEP (2011) Environmental Assessment of Ogoniland. United Nations Environment Programme, 139.

[28] Amnesty International and CEHRD (2011) The True Tragedy, Delays and Failures in Tackling Oil Spills in the Niger Delta. Amnesty International Index No: AFR/44/018/2011.

[29] NAOC (2004) Oil Spill Statistics from 1990-2004. Nigerian Agip Oil Company.

[30] Shell Petroleum Development Company, SPDC (2013) Nigerian Environment Brief.

[31] Archer, R. (1994) Markets and Good Governmen. In: Clayton, A., Ed., Governance, Democracy and Conditionality: What Role for NGOs? INTRAC, Oxford, 37-49. 


\section{Appendix A}

\section{National Oil Spill Detection and Response Agency Joint Investigation Visit (JIV) Form}

Note: This JIV Form is to be completed and signed by all participating parties in the field

1) Company:

2) Type of Complaint/Incident:
$\square$ Oil Pollution
Fire/Explosion
Drilling Mud/Chemical Pollution
$\square$ Others (Specify)

3) Incident Details

a) Date of incident:

b) Date first reported:

c) Date of first investigation:

d) Date of follow-up investigation:

e) Time investigation started:

f) Estimated quantity spilled:

4) Site Details

a) Site/Location:

b) Position of Spill/Leak:

c) Spill Area:
$\square$ Land
$\square$ Swamp
$\square$ Freshwater
$\square$ Mangrove Coastline
$\square$ Near shore
$\square$ Offshore
$\square$ Others (Specify)

5) Circumstances round Spill Point

a) Visual observation of Hole Position
$\square$ 120. Clock
$\square$ 100. Clock
$\square$ 20. Clock
30. Clock
$\square$ 40. Clock
$\square$ 50. Clock
$\square$ 60. Clock

b) Type of oil Contaminant
$\square$ Crude Oil
$\square$ Condensate
$\square$ Chemicals
Refined Products
$\square$ Others (Specify)
c) Facility
$\square$ Pipeline
$\square$ Flow Line
Wellhead
$\square$ Manifold
$\square$ Flow Station $\square$ Rig
$\square$ Storage Tank
$\square$ Compressor Plant $\quad \square$ Others (Specify)

d) Cause of Spill

$\square$ Corrosion
Impact of Incident

Equipment Failure

$\square$ Third Party Interference

Accident

a) Properties Impacted by the incident
$\square$ Farmland
$\square$ Fish Pond
$\square$ Vegetation
$\square$ Fishing Net
Surface Water
$\square$ Venerable Objects
$\square$ Others (Specify)

b) Nature of impact
$\square$ Oil stained vegetation
Oil stained fishing nets
Dead floating fishes
Dead floating crabs
$\square$ withering of vegetation
Others

c) Delineation of impacted area

$\square$ Within company's facility/ROW $\quad \square$ Outside company's facility/ROW

7) Extent of impact

a) Community (Indicate name) Land (Indicate area in $\mathrm{m}^{2}$ )

i

i

ii

ii

iii

iii

iv

iv

b) Creeks/Creeks lets $\quad \square$ Tidal $\square$ Non-tidal 


\begin{tabular}{lll}
\hline NAME & DIRECTION OF SLICK & LENGTH OF SLICK
\end{tabular}

c) Swamp $\square$ Tidal $\square$ Non-tidal

\begin{tabular}{lll}
\hline NAME & DIRECTION OF SLICK & LENGTH OF SLICK
\end{tabular}

d) River $\quad \square$ Tidal $\quad \square$ Non-tidal

\begin{tabular}{lll}
\hline NAME & DIRECTION OF SLICK & LENGTH OF SLICK
\end{tabular}

e) Shoreline/water

\begin{tabular}{lll}
\hline NAME & DIRECTION OF SLICK & LENGTH OF SLICK
\end{tabular}

8) Photograph/Map/Chart Ref.
$\square$ Still Photographs
$\square$ Video Coverage
$\square$ Mapping

9) Sample taken

10) Investigation carried out by
$\square$ Foot
$\square$ Boat
$\square$ Aircraft

11) Remarks/Recommendation

12) Time Investigation ended

13) Name and Signature of Participants

- NOSDRA

a)

b)

c) 
- DPR

a)

b)

c)

- STATE MINISTRY OF ENVIRONMENT

a)

b)

c)

- LOCAL GOVERNMENT COUNCIL

a)

b)

c)

- COMPANY

a)

b)

c)

- COMMUNITY

a)

b)

c) 